\title{
Conduction disturbances after transcatheter aortic valve implantation procedures - predictors and management
}

\author{
Krzysztof Wilczek ${ }^{1}$, Rafał Reguła ${ }^{1}$, Kamil Bujak ${ }^{1}$, Piotr Chodór ${ }^{2}$, Michał Długaszek ${ }^{1}$, Mariusz Gąsior ${ }^{1}$ \\ ${ }^{1} 3^{\text {rd }}$ Chair and Department of Cardiology, SMDZ in Zabrze, Medical University of Silesia, Katowice, Poland \\ ${ }^{2}$ Department of Cardiology, Congenital Heart Diseases and Electrotherapy, SMDZ in Zabrze, Medical University of Silesia, Katowice, Poland
}

Adv Interv Cardiol 2016; 12, 3 (45): 203-211

DOI: 10.5114 /aic.2016.61640

\begin{abstract}
A bstract
Transcatheter aortic valve implantation (TAVI) has become a safe and efficient alternative to cardiac surgery in patients with severe aortic stenosis. In many countries the number of performed TAVI procedures equals the number of surgical implantations. Indications for TAVI are becoming more liberal, allowing a wider spectrum of patients to benefit from the advantages of transcatheter therapy. Due to its invasive nature, TAVI is associated with some complications such as conduction disturbances. Although these disturbances are usually not lethal, they have a great influence on patients' state and long term-survival. The most relevant and common are His' bundle branch blocks, atrioventricular blocks, and need for permanent pacemaker implantation. With the frequency at $10 \%$ to even $50 \%$, conduction abnormalities are among the most important TAVI-related adverse events. Risk factors for conduction disturbances include age, anatomy of the heart, periprocedural factors, type of implanted valve, and comorbidities. Severity of occurring complications varies; therefore selection of a proper treatment approach is required. Considered as the most effective management, permanent pacemaker implantation turned out to negatively influence both recovery and survival. Moreover, there is no expert consensus on use of resynchronization therapy after TAVI. In this paper, the authors present a comprehensive analysis of the most common conduction disturbances accompanying TAVI, factors related to their occurrence, and treatment approach.
\end{abstract}

Key words: transcatheter aortic valve implantation, complications, conduction disturbances, permanent pacemaker implantation.

\section{Introduction}

Introduced in 2002 by Alain Cribier, transcatheter aortic valve implantation (TAVI) has become a well-established therapeutic option for high-risk patients or those unfit for open surgery with severe symptomatic aortic stenosis (AS) [1, 2]. The development of this method was appreciated by both the European Society of Cardiology (ESC) and the American Heart Association (AHA). Current ESC guidelines on the management of valvular heart diseases recommend TAVI in patients with severe symptomatic AS who are not suitable for surgical aortic valve replacement (SAVR) as assessed by a 'heart team' and who are likely to gain improvement in their quality of life (class of recommendation I, evidence level B) and allow it to be considered in high-risk patients with severe symptomatic AS who may still be suitable for surgery, but in whom TAVI is favoured by a 'heart team' (class of recommendation Ila, evidence level B) [3]. Similar indications are listed in the ACC/AHA guidelines with a note that TAVI is not recommended in patients in whom existing comorbidities would preclude the expected benefit from correction of AS [4].

Transcatheter aortic valve implantation carries the burden of possibility of multiple complications associated with the same procedure, used prosthesis, and patient's general state. The Valve Academic Research Consortium (VARC) 2 criteria provide definitions of frequently encountered complications, including myocardial infarction, stroke, vascular and bleeding complications, renal insufficiency, paravalvular leak, and last but not least, arrhythmias and conduction disturbances [5]. Among these complications, the development of post-procedural conduction disturbances may not be the strongest predictor of mortality but has a significant influence on long-term prognosis and patients' quality of life [6, 7]. A list of these abnormalities is presented in Table I.

Two devices have been most frequently used in clinical practice: the self-expanding Medtronic CoreValve prosthesis (CV - Medtronic Inc., Minneapolis, MN, USA), and the balloon-expandable Edwards SAPIEN/XT pros-

\section{Corresponding author:}

Krzysztof Wilczek MD, PhD, $3^{\text {rd }}$ Chair and Department of Cardiology, SMDZ in Zabrze, Medical University of Silesia, 9 M. Skłodowskiej Curie St, 41-800 Zabrze, Poland, phone: +48 3237336 09, e-mail: wilky@poczta.onet.pl

Received: 12.02 .2016 , accepted: 29.06.2016. 
Table I. Transcatheter aortic valve implantationrelated conduction disturbances and arrhythmias (according to VARC-2 [5])

- Implant-related new or worsened cardiac conduction disturbanc es (atrioventricular (AV) block of any degree, His' bundle branch and fascicular blocks, other intraventricular conduction defects) transient or persistent.

- New permanent pacemaker (PPM) implantation.

- New-onset atrial fibrillation or flutter.

- Any new arrhythmia resulting in hemodynamic instability or requiring therapy.

thesis (ES - Edwards Lifesciences, Irvine, CA, USA). Due to the different expansion of these valves, the nature and frequency of conduction disturbances in these 2 cases are slightly different [8]. During the last few years, new TAVI devices have been presented, such as the Acurate (Symetis, Lausanne, Switzerland), Portico (St. Jude Medical, Saint Paul, MN, USA), Engager (Medtronic Inc., Minneapolis, MN, USA), Jena Valve (Jena Valve Technology, Munich, Germany), Lotus (Boston Scientific, Marlborough, MA, USA), and Direct Flow Medical (Direct Flow Medical Inc., Santa Rosa, CA, USA). However, the aforementioned prostheses will not be widely discussed in this article, due to the limited number of analyses and evidence considering their relation to conduction disturbances.

In this paper, the authors present a review of the most frequent conduction disturbances related to TAVI, its risk factors, and the treatment approach.

\section{Types of disturbances}

\section{Atrioventricular block}

Atrioventricular block (AVB) is a conduction defect affecting impulses from the atria to the ventricles. Atrioventricular conduction abnormalities are well-known complications among patients undergoing SAVR as a result of AV node damage. Therefore it is no surprise when AVB occurs also after TAVI [9]. There is an analysis reporting even $1^{\text {st }}$ degree AVB as a predictor of new PPM implantation at 30 days after TAVI [10].

\section{His bundle-related disturbances and intraventricular conduction defects}

According to the anatomical localization of the defect, a few types of His bundle-related disturbances should be mentioned: left bundle branch block (LBBB), right bundle branch block (RBBB), left anterior hemiblock (LAH), and left posterior hemiblock (LPH). These disturbances are related to abnormal wall motion, causing a decrease in regional ejection fraction and an overall reduction in global ejection fraction (EF). Studies suggest that LBBB is the most frequent cause of such electromechanical contraction asynchrony and, in consequence, clinical deterioration [11]. New-onset LBBB after TAVI can be the cause of failure of left ventricular ejection fraction to improve in short- and long-term follow-up, despite the procedural success [7, 12, 13]. Some authors suggest that TAVI-induced LBBB increases the rate of all-cause and cardiovascular mortality $[14,15]$. Due to its frequency, with a range of $7 \%$ to $65 \%$, LBBB is one of the most relevant TAVI complications [16].

\section{Pacemaker implantation}

Permanent pacemaker requirement has been reported as a major complication of TAVI with a crude incidence rate of $15 \%$ [17]. Nonetheless, permanent stimulation is the most effective treatment of conduction disturbances. Therefore in this paper PPM implantation will be discussed in the treatment section.

\section{Risk factors for conduction disturbances}

\section{Anatomical factors}

The anatomy of the heart and its conduction system is intrinsically associated with the types of complications after invasive and surgical procedures. The AV node lies in the floor and the bundle of His courses from the AV node adjacent to the tricuspid valve and then down the interventricular septum. In the septum the His bundle divides into left and right branches coursing further down the septum and then spreading throughout the cardiac muscle via Purkinje fibres. The aortic valve annulus lies close to the parts of the conduction system, which puts the system at risk during aortic valve procedures [18]. In TAVI, in contrast to the surgical method, there is no replacement of a native valve but only implantation of a new prosthesis. During the procedure, high pressure is produced by valve expansion, resulting in trauma and ischemia of the conduction pathways. The trauma also causes oedema around the conduction tissue, which is associated with an increased leucocyte count after TAVI $[19,20]$. The pressure on the valvular apparatus and adjacent tissues is produced not only during the actual implantation but also during the balloon valvuloplasty performed before and/or after the device insertion. Size of the balloon catheter is adjusted accordingly on the basis of imaging studies, which cannot always provide accurate measurements. Studies have shown that the oversizing of the balloon used (high balloon/annulus ratio) is an independent predictor for a new AVB after TAVI but without an influence on $P M M$ requirement in multivariate analysis [19, 21]. Bleiziffer et al. also reported the link between the balloon size and the incidence of new conduction disturbances [21]. Similarly to this, a too large valve implanted into a small annulus was reported as a factor increasing the frequency of conduction disturbances. The implanted aortic prosthesis also generates pressure on structures located below the annulus, e.g. the interventricular septum. Compression depends not only on the size of the device but also on left ventricle outflow tract (LVOT) thickness. One of the TAVI-related studies showed 
that narrow LVOT correlates with increased frequency of intraventricular conduction disturbances. Furthermore, the LVOT/annulus ratio was an independent predictor for PPM implantation, independently of the thickness of the interventricular septum [22].

The unfavourable anatomy of the structures above the aortic annulus could also influence the conduction abnormalities. Pereira et al. reported a possible relationship between the ventricular pacing needs and the annulus-to-aorta angle, with an angle above $30^{\circ}$ as a predictor for pacing percentages above $10 \%$. They also reported that the porcelain (highly calcified) aorta can influence the development of PPM dependency at follow-up [23].

The degenerative type AS is most often caused by calcifications located in the valvular structures. Increasing area of calcifications causes thickening of coronary cusps and decreases the distance between the noncoronary cusp and the left bundle branch [24, 25]. Noncoronary cusp thickness above $8 \mathrm{~mm}$ was identified as a predictor for PPM implantation with $75 \%$ sensitivity and $100 \%$ specificity [26]. The severity of mitral annular calcification was also described as predicting the need for permanent pacing [27].

\section{Type of device and implantation procedure}

The anatomy of the heart is associated with the type of the implanted valve. The two most widely used valves (CV and ES) have substantial construction differences. CV is a device with a self-expanding, nitinol frame, whereas ES is balloon-expandable and has a lower profile. Due to the self-expanding nature of the nitinol stent, the radial force is essentially dependent on the diameter of the LVOT, while for the balloon-expandable valve the radial force produced is influenced by both the geometry and stiffness of the heart tissue [28]. Piazza et al. demonstrated that the occurrence of new-onset LBBB can be predicted on the basis of depth of CV implantation and the diameter of the prosthesis inflow portion [29]. Due to its size, the CV causes higher mechanical stress on the interventricular septum and the conduction pathways. Despite the shorter device frame and lower compression on the subvalvular septum, also ES implantation can result in LBBB occurrence [30]. In the study of Gutiérrez et al., a lower (ventricular) position of the valve relative to the anterior mitral leaflet was associated with a higher incidence of new LBBB [31]. However, still use of the CV prosthesis remains a stronger predictor for new-onset $L B B B$, with a 4-fold increase in frequency of LBBB compared with the ES device [32]. A few studies pointed out that, in the case of both CV and ES, too deep implantation was associated with increased LBBB occurrence [16, 27, 33]. Pereira et al. described the cut-off point for depth of CV implantation as $10.1 \mathrm{~mm}$ in LVOT with $87.5 \%$ sensitivity and $74 \%$ specificity for PPM requirement [23]. In the case of ES valves, higher (more aortic) implantation was also associated with lower risk of PPM requirement [34].
Too deep implantation occurs more frequently in the case of CV than ES implantation. Lenders et al. showed that use of a newer delivery system may help to solve this problem. In a study conducted using an Accutrack system, the authors reported a significant decrease in new LBBB occurrence or new PPM implantation in comparison with procedures performed with the old delivery system [10].

CV implantation is also an independent risk factor for high-grade AVB occurrence and need for PPM implantation $[17,35]$. These observations are supported by data from large registries in which CV implantation is associated with more frequent development of conduction abnormalities [14, 36]. Conduction disturbances occurring after ES device insertion are mostly temporary and infranodal [37].

In the section describing anatomical factors influencing conduction abnormalities the device/annulus ratio was mentioned. Oversizing of the prosthesis may result in new-onset disturbances, but even without mismatch, large devices are a more frequent cause of postprocedural LBBB. This relation is more noticeable in the case of the CV than the ES [32].

Unlike the CV and ES prostheses, the evidence concerning development of conduction disturbances associated with other prosthesis types is scarce. The highest rate of implanted prostheses occurs in the first generation Acurate device, with the frequency of new PPM implantation at $10 \%$ to $21 \%$ [38, 39]. Available analyses show a similar percentage of PPM implantations in the case of other new prostheses, e.g. Direct Flow Medical or Jena Valve $[6,39,40]$. The new version of the Acurate device (Symetis Acurate Neo) implanted via the transfemoral route seems to be less harmful for the conduction system. In the published data the periprocedural PPM implantation rate was not higher than 9\% [41-43].

Recently published data from studies investigating the Lotus prosthesis present a rate of postprocedural PPM implantation similar to CV. In the REPRISE II study, $28.6 \%$ of participants had a new PPM implanted during the perioperative period, mostly due to third-degree AVB. Overstretch of valve annulus or LVOT of $\geq 10 \%$ was identified as a strong independent predictor of the need for PPM implantation [44]. A similar PPM implantation frequency was reported by Rampat et al. in the LOTUS UK registry [45]. Due to a relatively high rate of conduction disturbances accompanying the first generation of TAVI prostheses, the decrease in this complication rate was one of the reasons for the introduction of improved valves. Medtronic CoreValve Evolut R, a new version of $\mathrm{CV}$, causes minimal conduction disturbances with a significantly lower rate of conduction abnormalities [46]. These findings are consistent with our experiences, both with CV and Evolut R prostheses. Similar outcomes were reported in the case of the new Acurate valve generation, as was mentioned before [41]. Only in the case of 
the new ES prosthesis generation (Sapien 3, ES3) was a higher rate of postprocedural conduction abnormalities and PPM implantations reported when compared to the Sapien XT devices. The longer stent of ES3, reaching deeper into the LVOT, could play a role, especially when low implantation was performed [34]. Height of implantation and relation of the prostheses to the adjacent structures in the most frequently used valves are presented in Figure 1.
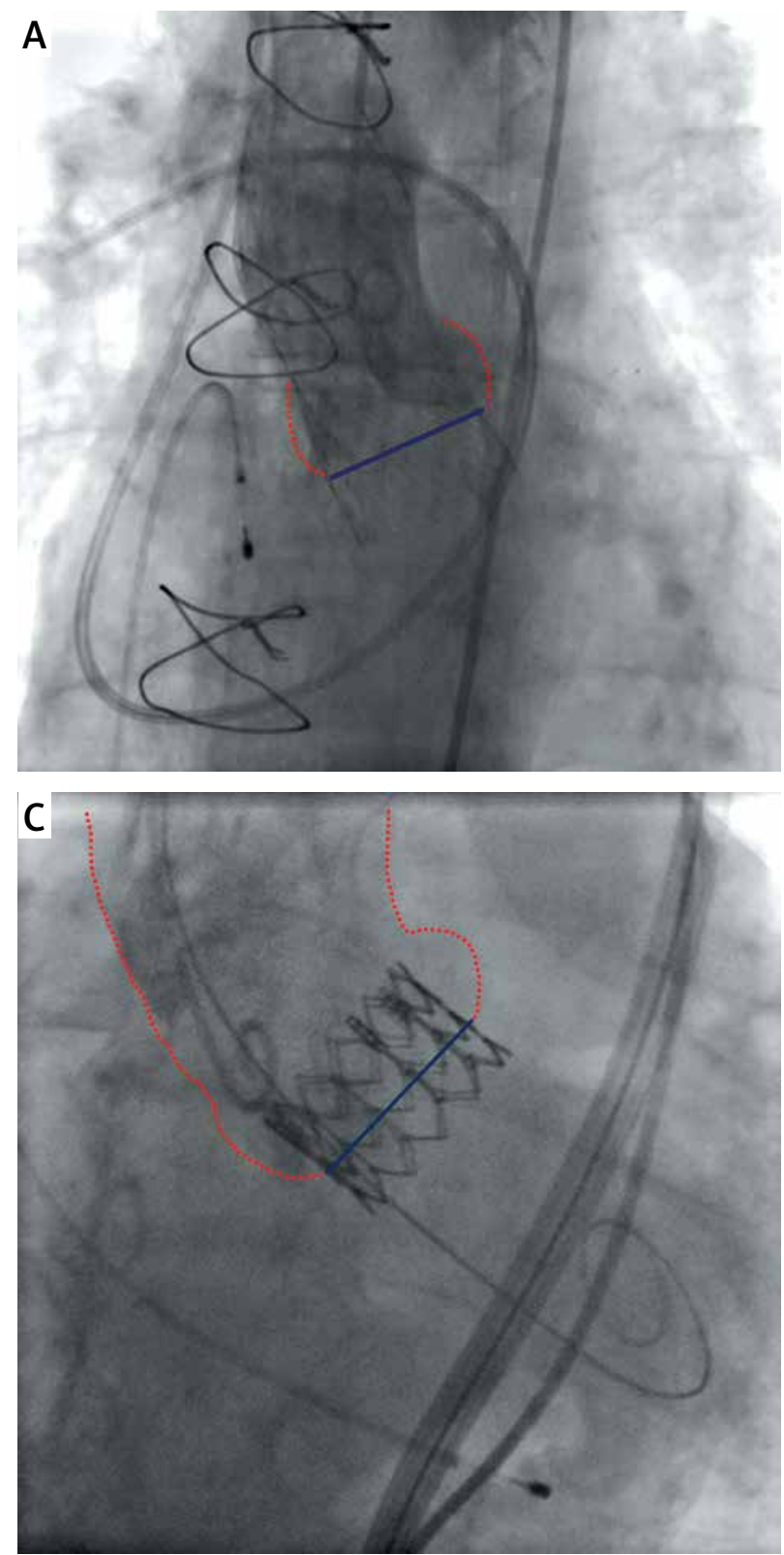

Rate of conduction disturbances and PPM implantations according to the valves used is presented in Table II. Data included in the table were obtained from published studies and registry analyses.

Actual implantation of the prosthesis is only one of several stages of the TAVI procedure. Other phases are: crossing of the aortic valve with a stiff wire, positioning and inflation of the balloon catheter (if necessary), and positioning of the device. Over a half of procedure-relat-
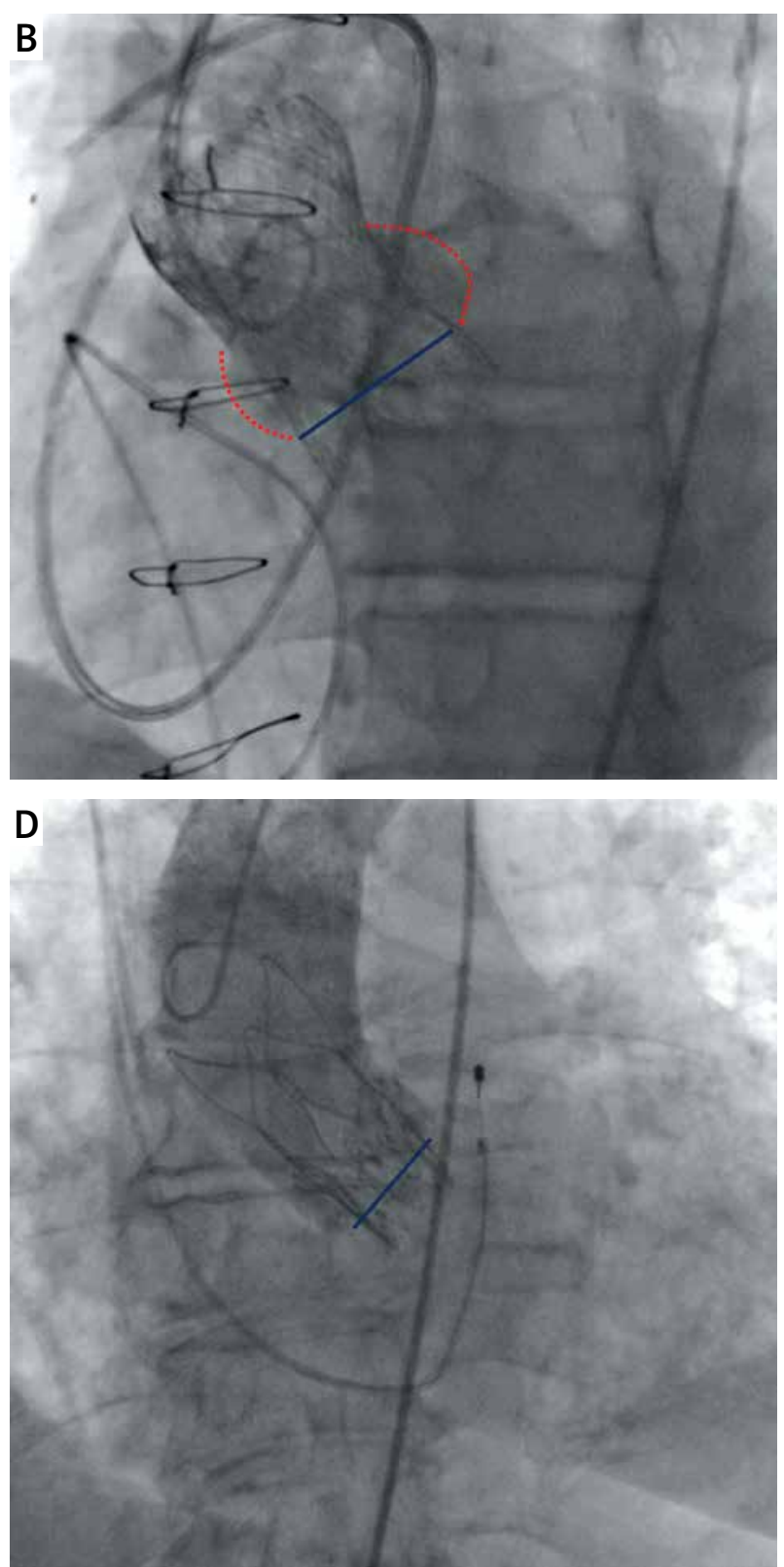

Figure 1. Most frequently used prostheses after implantation and their relation to the adjacent structures. Aortic annulus level was marked with blue lines, ascending aorta and coronary sinuses were marked with red dotted lines. A - CoreValve prosthesis, long stent of the valve may result in new conduction disturbances development. B - CoreValve Evolut R prosthesis, with shorter stent than first generation of CV may cause less trauma to the cardiac conduction system. $\mathbf{C}$ - SapienXT prosthesis, low profile allows the majority of abnormalities to be avoided. D - Symetis Acurate prosthesis, the part of the valve with thick struts is relatively short, which may correspond to rare occurrence of conduction disturbances. Source: authors' own material 
ed conduction abnormalities occur the first time even before the device implantation. The majority of these disturbances are caused by balloon predilatation. Rapid inflation of the balloon catheter and high pressures may irreversibly damage the AV node [19]. Nevertheless, valvuloplasty is useful in the case of severe calcifications of aortic cusps and in proper selection of prosthesis size. The authors tend to carefully select patients requiring predilatation and not to overuse this technique. Postdilatation of the implanted prosthesis also results in development of some new disturbances, pressing the valve closer to the AV node [32]. This may be however one of the simplest solutions in the case of severe perivalvular leak; therefore we believe that postdilatation may be used in a less restrictive manner than preprocedural valvuloplasty.

Due to the sheath and delivery system sizes, the delivery route in TAVI is related to some complications. They are mostly vascular or bleeding complications, not conduction disturbances. In a study conducted by Salizzoni et al. only the transapical access was related to postprocedural LBBB occurrence [47].

\section{Electrophysiological factors}

Pre-existing abnormalities in ECG play an important role in development of TAVI-related conduction disturbances. Abnormalities alone can be irrelevant for the prognosis, but in addition to the interventional procedure such as TAVI, they affect procedural success and follow-up. For example, isolated right bundle block is generally recognized as a benign condition, but it appears to be an independent predictor of development of new complete AVB and PPM implantation [6, 30, 48]. The LBBB, known as a TAVI-related complication itself, is also a predictor for postprocedural AVB and need for PPM implan-

Table II. Postprocedural frequency of most common new conduction disturbances occurring after transcatheter aortic valve implantation according to the device implanted. Case reports and case series were not taken into consideration

\begin{tabular}{|c|c|c|c|c|}
\hline Prosthesis & Disturbances & Clinical trials & $\begin{array}{l}\text { Registry analyses } \\
\text { (>100 participants) }\end{array}$ & $\begin{array}{c}\text { Registry analyses } \\
\text { (<100 participants })\end{array}$ \\
\hline \multirow[t]{3}{*}{ Core Valve } & LBBB & N/A & $38.8-50 \%[10,32]$ & $9-48 \%[19,35,48,50]$ \\
\hline & High-grade AVB & N/A & $4.6-16 \%[10,32]$ & $5.7-27 \%[19,33,35,50,51]$ \\
\hline & PPM implantation & $21.6 \%[63]$ & $6.9-27.4 \%[10,32,55,64]$ & $\begin{array}{c}5.6-55.9 \%[23,33,35,48 \\
50,51]\end{array}$ \\
\hline \multirow[t]{3}{*}{ CoreValve Evolut R } & LBBB & N/A & N/A & $8.3 \%[46]$ \\
\hline & High-grade AVB & N/A & N/A & $0[46]$ \\
\hline & PPM implantation & N/A & N/A & $0[46]$ \\
\hline \multirow[t]{3}{*}{ Sapien 3} & LBBB & N/A & $13 \%[34]$ & N/A \\
\hline & High-grade AVB & N/A & $17.9 \%[34]$ & N/A \\
\hline & PPM implantation & N/A & $7.2-19.1 \%[34,64]$ & N/A \\
\hline \multirow[t]{3}{*}{ Sapien/XT } & LBBB & N/A & $8.6-30.2 \%[12,32,34]$ & $5.1-7.9 \%[35,37,65]$ \\
\hline & High-grade AVB & N/A & $1.3-12.6 \%[32,34,66]$ & $2.6-5.1 \%[35,65]$ \\
\hline & PPM implantation & $3.4-8.5 \%[67-69]$ & $1.3-12.2 \%[12,32,34,66]$ & $3.6-5.3 \%[35,37,65]$ \\
\hline \multirow[t]{3}{*}{ Symetis Acurate } & LBBB & N/A & N/A & N/A \\
\hline & High-grade AVB & $2.5 \%[70]$ & N/A & N/A \\
\hline & PPM implantation & $2.5 \%[70]$ & $10 \%[38]$ & $21 \%[39]$ \\
\hline \multirow{3}{*}{$\begin{array}{l}\text { Symetis Acurate } \\
\text { Neo }\end{array}$} & LBBB & N/A & N/A & N/A \\
\hline & High-grade AVB & N/A & N/A & $0-8.7 \%[41-43]$ \\
\hline & PPM implantation & N/A & N/A & $0-8.7 \%[41-43]$ \\
\hline \multirow[t]{3}{*}{ Lotus } & LBBB & N/A & $55.2 \%[45]$ & N/A \\
\hline & High-grade AVB & $26 \%[44]$ & $20.2 \%[45]$ & N/A \\
\hline & PPM implantation & $28.6 \%[44]$ & $38.1 \%[45]$ & N/A \\
\hline
\end{tabular}

LBBB - left bundle branch block, AVB - atrioventricular block, PPM - permanent pacemaker, N/A - not available. 
tation [49]. Jilaihawi et al. found a correlation between left axis deviation in baseline ECG, with or without LBBB, and need for PPM implantation [26]. One could suspect that any increase in QRS duration may have an influence on development of conduction disturbances. It was confirmed in a few studies where longer baseline QRS duration was identified as a factor associated with a higher rate of persistent LBBB and permanent pacemaking [12, 29]. One of the studies described postprocedural QRS duration > 128 ms as associated with PPM requirement [33]. In studies using invasive electrophysiological studies to evaluate TAVI effects on the conduction system, also significant prolongation of His-ventricle interval and the Wenckebach point was found $[37,50]$.

Like the slower intraventricular conduction, the slower heart rate influences the prognosis after TAVI. One analysis showed that patients with a baseline or postprocedural ventricular rate below $65 / \mathrm{min}$ had six-fold increased risk for PPM requirement in contrast to patients with a higher heart rate. Baseline atrial fibrillation was also found as an independent risk factor for this complication [51].

In patients without electrocardiographic abnormalities at admission, some disturbances can occur during the TAVI procedure. These abnormalities can be transient, but some of them may have an influence on short- and long-term prognosis. Transient episodes of AVB and LBBB occurring during implantation are in follow-up risk factors for complete AVB development and in consequence PPM requirement [21].

\section{Other factors}

In the analysis conducted by Piazza et al. male sex and history of myocardial infarction were independent risk factors for new-onset LBBB in univariable analysis but not predictors of new PPM [29]. However, the requirement for PPM was significantly higher in patients with higher risk in the logistic EuroSCORE [52]. An association between high Logistic EuroSCORE and new-onset AVB or LBBB was not found, though [21, 32].

Patients' age is one of the variables included in the logistic EuroSCORE formula. Age itself was also described as an independent predictor of conduction disturbances after TAVI. Patients older than 75 years have a significantly higher rate of PPM implantation when compared to the younger group [51]. In a sub-analysis of the PARTNER trial, Nazif et al. also found that previous cardiac surgery was significantly more frequent in patients who developed LBBB after TAVI in comparison to patients without this abnormality [13].

\section{Treatment approach}

As the TAVI is a highly invasive procedure, continuous monitoring of patients after the implantation should be conducted. Close attention to rhythm and conduction disturbances, systemic blood pressure, fluid balance, and vascular accesses should be given. Duration of $48 \mathrm{~h}$ of such observation is considered as appropriate [53]. Careful monitoring during and after the procedure helps in faster identification and management of the conduction abnormalities. For a case of sudden high-degree AVB or bradycardia/bradyarrhythmia, a temporary electrode is implanted to secure the patient during the procedure. In some cases, the electrode could stay in the right ventricle longer due to the occurrence of some rhythm abnormalities.

There are no unified guidelines on time of continuous monitoring after TAVI. Most of the disturbances occur within the first week after the procedure. Therefore some researchers recommend at least 7-day ECG monitoring [17]. ESC guidelines on cardiac pacing also recommend a 7-day period of clinical observation to assess the type and significance of disturbances. The observation period could be shortened in case of permanent or recurring complete AVB with slow escape rhythm. In such patients the PPM implantation can be performed earlier (class of recommendation I, evidence level C) [54]. There is a lack of consensus and data regarding PPM implantation in case of occurrence of TAVI-related $2^{\text {nd }}$ degree AVB, bundle branch blocks or combination of AVB and bundle blocks, but most researchers recommend permanent pacing $[17$, $54,55]$. Currently, the median time to the clinical decision of implantation is 5 days. Due to the possibility of resolution of conduction abnormalities, some authors recommend a longer observation period and a more conservative approach to PPM implantation [55].

While considering the PPM implantation after TAVI, one should also take into account an interventional procedure in a short period. In the analysis of Schwerg et al., PPM implantation on the day of TAVI compared to later implantation was not associated with additional complications [56].

The TAVI-related conduction disturbances may resolve not only during the hospital stay but also in a longer period. Results of the investigations concerning patients with PPM implanted after TAVI are not consistent. Nonetheless, a significant decrease in pacing dependency is observed $[57,58]$. The lowest ventricular pacing rate was observed in patients in whom PPM implantation was performed due to bundle branch blocks $[35,55]$.

While some studies report that PPM appears to have a neutral or even positive influence on survival, in the sub-analysis of the PARTNER trial the presence of PPM was associated with worse outcomes and higher 1-year mortality when compared to non-PPM patients [6, 59, 60]. Considering this, a careful analysis of PPM indications in each case should be performed. The authors believe that patient observation instead of premature PPM implantation is more appropriate, especially since the majority of conduction disturbances tend to disappear before discharge. 
Although many patients undergoing TAVI meet the criteria for cardiac resynchronisation therapy (CRT), there are limited data and experience considering the influence of resynchronisation on outcome. Only a few case reports concerning use of cardiac CRT devices in patients after TAVI are available $[61,62]$. These papers describe very good outcomes of combined TAVI-CRT therapy; therefore further evaluation of resynchronisation therapy following TAVI should be performed, especially since LBBB was recognised as a mortality-affecting factor [15].

\section{Conclusions}

The development of TAVI is dynamic, and the growing number of patients suggests that in the immediate future the percentage of transcatheter procedures will be comparable to surgical ones. Indications for TAVI can also be expanded. Therefore, patients should be carefully screened for risk factors for conduction disturbances in order to provide effective prevention and proper treatment. Pacemaker implantation is the most common treatment option for severe abnormalities, but data regarding its use and influence on outcome remain ambiguous. Guidelines or standardized protocols of management with conduction disturbances should also be developed in order to ensure optimal standards of care in every case.

\section{Conflict of interest}

The authors declare no conflict of interest.

\section{References}

1. Mack MJ, Leon MB, Smith CR, et al. 5-year outcomes of transcatheter aortic valve replacement or surgical aortic valve replacement for high surgical risk patients with aortic stenosis (PARTNER 1): a randomised controlled trial. Lancet 2015; 385: 2477-84.

2. Kapadia SR, Leon MB, Makkar RR, et al. 5-year outcomes of transcatheter aortic valve replacement compared with standard treatment for patients with inoperable aortic stenosis (PARTNER 1): a randomised controlled trial. Lancet 2015; 385: 2485-91.

3. Vahanian A, Alfieri O, Andreotti F, et al. Guidelines on the management of valvular heart disease (version 2012). Eur Heart $J$ 2012; 33: 2451-96.

4. Nishimura RA, Otto CM, Bonow RO, et al. 2014 AHA/ACC guideline for the management of patients with valvular heart disease: a report of the American College of Cardiology/American Heart Association Task Force on Practice Guidelines. J Thorac Cardiovasc Surg 2014; 148: e1-132.

5. Kappetein AP, Head SJ, Généreux P, et al. Updated standardized endpoint definitions for transcatheter aortic valve implantation. J Am Coll Cardiol 2012; 60: 1438-54.

6. Martinez-Selles M, Bramlage P, Thoenes M, Schymik G. Clinical significance of conduction disturbances after aortic valve intervention: current evidence. Clin Res Cardiol 2015; 104: 1-12.

7. Hoffmann R, Herpertz R, Lotfipour S, et al. Impact of a new conduction defect after transcatheter aortic valve implantation on left ventricular function. JACC Cardiovasc Interv 2012; 5: 1257-63.
8. Neragi-Miandoab S, Michler RE. A review of most relevant complications of transcatheter aortic valve implantation. ISRN Cardiol 2013; 2013: 956252.

9. Roten L, Stortecky S, Scarcia F, et al. Atrioventricular conduction after transcatheter aortic valve implantation and surgical aortic valve replacement. J Cardiovasc Electrophysiol 2012; 23: 1115-22.

10. Lenders GD, Collas V, Hernandez JM, et al. Depth of valve implantation, conduction disturbances and pacemaker implantation with CoreValve and CoreValve Accutrak system for Transcatheter Aortic Valve Implantation, a multi-center study. Int J Cardiol 2014; 176: 771-5.

11. Zannad F, Huvelle E, Dickstein K, et al. Left bundle branch block as a risk factor for progression to heart failure. Eur J Heart Fail 2007; 9: 7-14.

12. Urena $M$, Mok $M$, Serra V, et al. Predictive factors and long-term clinical consequences of persistent left bundle branch block following transcatheter aortic valve implantation with a balloon-expandable valve. J Am Coll Cardiol 2012; 60: 1743-52.

13. Nazif TM, Williams MR, Hahn RT, et al. Clinical implications of new-onset left bundle branch block after transcatheter aortic valve replacement: analysis of the PARTNER experience. Eur Heart J 2014; 35: 1599-607.

14. Schymik G, Tzamalis P, Bramlage P, et al. Clinical impact of a new left bundle branch block following TAVI implantation: 1-year results of the TAVIK cohort. Clin Res Cardiol 2015; 104: 351-62.

15. Houthuizen P, Van Garsse LAFM, Poels TT, et al. Left bundlebranch block induced by transcatheter aortic valve implantation increases risk of death. Circulation 2012; 126: 720-8.

16. Poels TT, Houthuizen P, Van Garsse LAFM, et al. Transcatheter aortic valve implantation-induced left bundle branch block: causes and consequences. J Cardiovasc Transl Res 2014; 7: 395-405.

17. Erkapic D, De Rosa S, Kelava A, et al. Risk for permanent pacemaker after transcatheter aortic valve implantation: a comprehensive analysis of the literature. J Cardiovasc Electrophysiol 2012; 23: 391-7.

18. Ghadimi K, Patel PA, Gutsche JT, et al. Perioperative conduction disturbances after transcatheter aortic valve replacement. J Cardiothorac Vasc Anesth 2013; 27: 1414-20.

19. Nuis RJ, Van Mieghem NM, Schultz CJ, et al. Timing and potential mechanisms of new conduction abnormalities during the implantation of the Medtronic CoreValve System in patients with aortic stenosis. Eur Heart J 2011; 32: 2067-74.

20. Moreno R, Dobarro D, López De Sá E, et al. Cause of complete atrioventricular block after percutaneous aortic valve implantation: insights from a necropsy study. Circulation 2009; 120 : 29-31.

21. Bleiziffer S, Ruge H, Hörer J, et al. Predictors for new-onset complete heart block after transcatheter aortic valve implantation. JACC Cardiovasc Interv 2010; 3: 524-30.

22. Toutouzas K, Synetos A, Tousoulis D, et al. Predictors for permanent pacemaker implantation after core valve implantation in patients without preexisting ECG conduction disturbances: the role of a new echocardiographic index. Int J Cardiol 2014; 172: 601-3.

23. Pereira E, Ferreira N, Caeiro D, et al. Transcatheter aortic valve implantation and requirements of pacing over time. Pacing Clin Electrophysiol 2013; 36: 559-69.

24. Wasilewski J, Mirota K, Wilczek K, et al. Calcific aortic valve damage as a risk factor for cardiovascular events. Pol J Radiol 2012; 77: 30-4. 
25. Khawaja MZ, Rajani R, Cook A, et al. Permanent pacemaker insertion after CoreValve transcatheter aortic valve implantation: incidence and contributing factors (the UK CoreValve Collaborative). Circulation 2011; 123: 951-60.

26. Jilaihawi $H$, Chin D, Vasa-Nicotera $M$, et al. Predictors for permanent pacemaker requirement after transcatheter aortic valve implantation with the CoreValve bioprosthesis. Am Heart J 2009; 157: 860-6.

27. Baan J, Yong ZY, Koch KT, et al. Factors associated with cardiac conduction disorders and permanent pacemaker implantation after percutaneous aortic valve implantation with the CoreValve prosthesis. Am Heart J 2010; 159: 497-503.

28. Tzamtzis S, Viquerat J, Yap J, Mullen MJ, Burriesci G. Numerical analysis of the radial force produced by the Medtronic-CoreValve and Edwards-SAPIEN after transcatheter aortic valve implantation (TAVI). Med Eng Phys 2013; 35: 125-30.

29. Piazza N, Nuis RJ, Tzikas A, et al. Persistent conduction abnormalities and requirements for pacemaking six months after transcatheter aortic valve implantation. Eurolntervention 2010; 6: 475-84.

30. Erkapic D, Kim WK, Weber M, et al. Electrocardiographic and further predictors for permanent pacemaker requirement after transcatheter aortic valve implantation. Europace 2010; 12 : 1188-90.

31. Gutiérrez M, Rodés-Cabau J, Bagur R, et al. Electrocardiographic changes and clinical outcomes after transapical aortic valve implantation. Am Heart J 2009; 158: 302-8.

32. Franzoni I, Latib A, Maisano F, et al. Comparison of incidence and predictors of left bundle branch block after transcatheter aortic valve implantation using the CoreValve versus the Edwards valve. Am J Cardiol 2013; 112: 554-9.

33. Mouillet G, Lellouche N, Lim P, et al. Patients without prolonged QRS after TAVI with CoreValve device do not experience high-degree atrio-ventricular block. Catheter Cardiovasc Interv 2013; 81: 882-7.

34. De Torres-Alba F, Kaleschke G, Diller GP, et al. Changes in the pacemaker rate after transition from Edwards SAPIEN XT to SAPIEN 3 transcatheter aortic valve implantation. JACC Cardiovasc Interv 2016; 9: 805-13.

35. Ramazzina C, Knecht S, Jeger R, et al. Pacemaker implantation and need for ventricular pacing during follow-up after transcatheter aortic valve implantation. Pacing Clin Electrophysiol 2014; 37: 1592-601.

36. Rodés-Cabau J, Webb JG, Cheung A, et al. Transcatheter aortic valve implantation for the treatment of severe symptomatic aortic stenosis in patients at very high or prohibitive surgical risk. Acute and late outcomes of the multicenter Canadian experience. J Am Coll Cardiol 2010; 55: 1080-90.

37. Eksik A, Gul M, Uyarel H, et al. Electrophysiological evaluation of atrioventricular conduction disturbances in transcatheter aortic valve implantation with Edwards SAPIEN prosthesis. J Invasive Cardiol 2013; 25: 305-9.

38. Kempfert J, Holzhey D, Hofmann S, et al. First registry results from the newly approved ACURATE TATM TAVI system. Eur J Cardiothorac Surg 2015; 48: 137-41.

39. Seiffert M, Conradi L, Kloth B, et al. Single-centre experience with next-generation devices for transapical aortic valve implantation. Eur J Cardiothorac Surg 2015; 47: 39-45; discussion 45.

40. Schofer J, Colombo A, Klugmann S, et al. Prospective multicenter evaluation of the direct flow medical transcatheter aortic valve. J Am Coll Cardiol 2014; 63: 763-8.
41. Zembala M, Hawranek M, Wacławski J, et al. Symetis Acurate Neo - pierwsze polskie doświadczenia z zastawką TAVI drugiej generacji wprowadzaną przezskórnie. Kardiol Pol 2016; 74: 206-12.

42. Maeda K, Kuratani T, Torikai K, et al. New self-expanding transcatheter aortic valve device for transfemoral implantation early results of the first-in-Asia implantation of the ACURATE Neo/TF System. Circ J 2015; 79: 1037-43.

43. Schaefer A, Treede H, Schoen G, et al. Improving outcomes: case-matched comparison of novel second-generation versus first-generation self-expandable transcatheter heart valves. Eur J Cardiothorac Surg 2016; ezw021 [Epub ahead of print].

44. Meredith Am IT, Walters DL, Dumonteil N, et al. Transcatheter aortic valve replacement for severe symptomatic aortic stenosis using a repositionable valve system: 30-day primary endpoint results from the REPRISE II study. J Am Coll Cardiol 2014; 64: 1339-48.

45. Rampat R, Khawaja MZ, Byrne J, et al. Transcatheter aortic valve replacement using the repositionable LOTUS valve: United Kingdom experience. JACC Cardiovasc Interv 2016; 9: 367-72.

46. Muñoz-García AJ, Pascual I, Avanzas P, et al. New generation CoreValve EvolutTM R 23mm aortic valve prosthesis: initial experience. Rev Española Cardiol (English ed.) 2015; 68: 721-2.

47. Salizzoni S, Anselmino M, Fornengo C, et al. One-year follow-up of conduction disturbances following transcatheter aortic valve implantation. J Cardiovasc Med (Hagerstown) 2015; 16: 296-302.

48. Piazza N, Onuma Y, Jesserun E, et al. Early and persistent intraventricular conduction abnormalities and requirements for pacemaking after percutaneous replacement of the aortic valve. JACC Cardiovasc Interv 2008; 1: 310-6.

49. Carrabba N, Valenti R, Migliorini A, et al. Impact on left ventricular function and remodeling and on 1-year outcome in patients with left bundle branch block after transcatheter aortic valve implantation. Am J Cardiol 2015; 116: 125-31.

50. Rubín JM, Avanzas P, Del Valle R, et al. Atrioventricular conduction disturbance characterization in transcatheter aortic valve implantation with the corevalve prosthesis. Circ Cardiovasc Interv 2011; 4: 280-6.

51. Schroeter T, Linke A, Haensig M, et al. Predictors of permanent pacemaker implantation after Medtronic CoreValve bioprosthesis implantation. Europace 2012; 14: 1759-63.

52. Saia F, Lemos PA, Bordoni B, et al. Transcatheter aortic valve implantation with a self-expanding nitinol bioprosthesis: prediction of the need for permanent pacemaker using simple baseline and procedural characteristics. Catheter Cardiovasc Interv 2012; 79: 712-9.

53. Ussia GP, Scarabelli $M$, Mulè $M$, et al. Postprocedural management of patients after transcatheter aortic valve implantation procedure with self-expanding bioprosthesis. Catheter Cardiovasc Interv 2010; 76: 757-66.

54. Brignole M, Auricchio A, Baron-Esquivias G, et al. 2013 ESC Guidelines on cardiac pacing and cardiac resynchronization therapy: the Task Force on cardiac pacing and resynchronization therapy of the European Society of Cardiology (ESC). Developed in collaboration with the European Heart Rhythm Association. Eur Heart J 2013; 34: 2281-329.

55. Bjerre Thygesen J, Loh PH, Cholteesupachai J, et al. Reevaluation of the indications for permanent pacemaker implantation after transcatheter aortic valve implantation. J Invasive Cardiol 2014; 26: 94-9.

56. Schwerg M, Baldenhofer G, Dreger H, et al. Complete atrioventricular block after TAVI: when is pacemaker implantation safe? Pacing Clin Electrophysiol 2013; 36: 898-903. 
57. Renilla A, Rubín JM, Rozado J, Moris C. Long-term evolution of pacemaker dependency after percutaneous aortic valve implantation with the corevalve prosthesis. Int J Cardiol 2015; 201: 61-3.

58. van der Boon RMA, Van Mieghem NM, Theuns DA, et al. Pacemaker dependency after transcatheter aortic valve implantation with the self-expanding Medtronic CoreValve System. Int I Cardiol 2013; 168: 1269-73.

59. Buellesfeld L, Stortecky S, Heg D, et al. Impact of permanent pacemaker implantation on clinical outcome among patients undergoing transcatheter aortic valve implantation. J Am Coll Cardiol 2012; 60: 493-501.

60. Dizon JM, Nazif TM, Hess PL, et al. Chronic pacing and adverse outcomes after transcatheter aortic valve implantation. Heart 2015; 101: 1665-71.

61. Meguro K, Lellouche N, Teiger E. Cardiac resynchronization therapy improved heart failure after left bundle branch block during transcatheter aortic valve implantation. J Invasive Cardiol 2012; 24: 132-3.

62. Osmancik P, Stros P, Herman D, et al. Cardiac resynchronization therapy implantation following transcatheter aortic valve implantation. Europace 2011; 13: 290-1.

63. Barker CM, Reardon MJ. The CoreValve US pivotal trial. Semin Thorac Cardiovasc Surg 2014; 26: 179-86.

64. Blackman DJ, Baxter PD, Gale CP, et al. Do outcomes from transcatheter aortic valve implantation vary according to access route and valve type? The UK TAVI Registry. J Interv Cardiol 2014; 27: 86-95.

65. Binder RK, Webb JG, Toggweiler S, et al. Impact of post-implant SAPIEN XT geometry and position on conduction disturbances, hemodynamic performance, and paravalvular regurgitation. JACC Cardiovasc Interv 2013; 6: 462-8.

66. Bagur R, Rodés-Cabau J, Gurvitch R, et al. Need for permanent pacemaker as a complication of transcatheter aortic valve implantation and surgical aortic valve replacement in elderly patients with severe aortic stenosis and similar baseline electrocardiographic findings. JACC Cardiovasc Interv 2012; 5: 540-51.

67. Leon MB, Smith CR, Mack M, et al. Transcatheter aortic-valve implantation for aortic stenosis in patients who cannot undergo surgery. N Engl J Med 2010; 363: 1597-607.

68. Smith CR, Leon MB, Mack MJ, et al. Transcatheter versus surgical aortic-valve replacement in high-risk patients. N Engl J Med 2011; 364: 2187-98.

69. Leon MB, Smith CR, Mack MJ, et al. Transcatheter or surgical aortic-valve replacement in intermediate-risk patients. N Engl J Med 2016; 374: 1609-20.

70. Kempfert J, Rastan AJ, Beyersdorf F, et al. Trans-apical aortic valve implantation using a new self-expandable bioprosthesis: initial outcomes. Eur J Cardiothorac Surg 2011; 40: 1114-9. 